\title{
Skeletal muscle and performance adaptations to high-intensity training in elite male soccer players: speed endurance runs versus small-sided game training
}

\author{
Dan Fransson ${ }^{1} \cdot$ Tobias Schmidt Nielsen $^{2} \cdot$ Karl Olsson $^{3} \cdot$ Tobias Christensson $^{1}$ • \\ Paul S. Bradley ${ }^{4}$ Ioannis G. Fatouros $^{5} \cdot$ Peter Krustrup $^{6,7}$. \\ Nikolai Baastrup Nordsborg ${ }^{2}$ Magni Mohr ${ }^{1,6,8}$
}

Received: 18 June 2017 / Accepted: 24 October 2017 / Published online: 8 November 2017

(C) The Author(s) 2017. This article is an open access publication

\begin{abstract}
Purpose To examine the skeletal muscle and performance responses across two different exercise training modalities which are highly applied in soccer training.

Methods Using an RCT design, 39 well-trained male soccer players were randomized into either a speed endurance training (SET; $n=21$ ) or a small-sided game group (SSG; $n=18$ ). Over 4 weeks, thrice weekly, SET performed $6-10 \times 30$-s all-out runs with 3 -min recovery, while SSG completed $2 \times 7-9-$ min small-sided games with 2 -min
\end{abstract}

Communicated by Olivier Seynnes.

Magni Mohr

magnim@setur.fo

1 Department of Food and Nutrition, and Sport Science, Center for Health and Human Performance, University of Gothenburg, Gothenburg, Sweden

2 Department of Nutrition, Exercise and Sports, University of Copenhagen, Copenhagen, Denmark

3 Department of Health and Caring Sciences, Linnaeus University, Kalmar, Sweden

4 Research Institute of Sport and Exercise Sciences, Liverpool John Moores University, Liverpool, UK

5 School of Physical Education and Sport Science, University of Thessaly, Karies, Trikala, Greece

6 Department of Sports Science and Clinical Biomechanics, SDU Sport and Health Sciences Cluster (SHSC), University of Southern Denmark, Odense, Denmark

7 Sport and Health Sciences, College of Life and Environmental Sciences, University of Exeter, Exeter, UK

8 Faculty of Health Sciences, Centre of Health Science, University of the Faroe Islands, Jónas Broncks gøta 25. 3rd floor, Tórshavn, Faroe Islands recovery. Muscle biopsies were obtained from m. vastus lateralis pre and post intervention and were subsequently analysed for metabolic enzyme activity and muscle protein expression. Moreover, the Yo-Yo Intermittent Recovery level 2 test (Yo-Yo IR2) was performed.

Results Muscle CS maximal activity increased $(P<0.05)$ by $18 \%$ in SET only, demonstrating larger $(P<0.05)$ improvement than SSG, while HAD activity increased $(P<0.05)$ by $24 \%$ in both groups. $\mathrm{Na}^{+}-\mathrm{K}^{+}$ATPase $\alpha_{1}$ subunit protein expression increased $(P<0.05)$ in SET and SSG (19 and 37\%, respectively), while MCT4 protein expression rose $(P<0.05)$ by 30 and $61 \%$ in SET and SSG, respectively. SOD2 protein expression increased $(P<0.05)$ by 28 and $37 \%$ in SET and SSG, respectively, while GLUT-4 protein expression increased $(P<0.05)$ by $40 \%$ in SSG only. Finally, SET displayed $39 \%$ greater improvement $(P<0.05)$ in Yo-Yo IR2 performance than SSG.

Conclusion Speed endurance training improved muscle oxidative capacity and exercise performance more pronouncedly than small-sided game training, but comparable responses were in muscle ion transporters and antioxidative capacity in well-trained male soccer players.

Keywords Antioxidant capacity - Intermittent exercise Muscle fatigue $\cdot$ Muscle oxidative capacity $\cdot \mathrm{Na}^{+}-\mathrm{K}^{+}$ ATPase activity $\cdot$ Football

$\begin{array}{ll}\text { Abbreviations } & \\ \text { AAT } & \text { Arrowhead agility test } \\ \text { ANOVA } & \text { Analysis of variance } \\ \text { ATP } & \text { Adenosine triphosphate } \\ \text { BSA } & \text { Bovine serum albumin } \\ \text { CAT } & \text { Catalase } \\ \text { CS } & \text { Citrate synthase } \\ \text { CV } & \text { Coefficient of variation }\end{array}$




$\begin{array}{ll}\text { DTT } & \text { Dithiothreitol } \\ \text { EDTA } & \text { Ethylenediaminetetraacetic acid } \\ \text { EGTA } & \text { Ethylene glycol tetraacetic acid } \\ \text { ES } & \text { Effect size } \\ \text { FXYD1 } & \text { Phospholemman protein } \\ \text { GLUT-4 } & \text { Glucose transporter type } 4 \\ \text { GPX } & \text { Glutathione peroxidase } \\ \text { HAD } & \text { Beta-hydroxyacyl-CoA-dehydrogenase } \\ \text { HCl } & \text { Hydrogen chloride } \\ \text { HEPES } & \text { 4-(2-Hydroxyethyl)-1-piperazineethane- } \\ & \text { sulfonic acid } \\ \text { HIR } & \text { High-intensity running distance } \\ & \text { ( } m>14 \text { km/h) } \\ \text { HRP } & \text { Horseradish peroxidase } \\ \text { HSR } & \text { High-speed running distance } \\ & \text { ( } m>21 \text { km/h) } \\ \text { Ia } & \text { Intense accelerations }\left(n>3 \text { m/s }{ }^{2} \text { ) }\right. \\ \text { Id } & \text { Intense decelerations }\left(n>3 \text { m/s }{ }^{2}\right) \\ \text { MCT4 } & \text { Monocarboxylate transporter } 4 \\ \text { NaCl } & \text { Sodium chloride } \\ \text { Na3VO4 } & \text { Sodium orthovanadate } \\ \text { NF-kB } & \text { Nuclear factor kappa-light-chain- } \\ & \text { enhancer of activated B cells } \\ \text { NHE1 } & \text { Na }{ }^{+} / \mathrm{H}^{+} \text {exchanger isoform 1 } \\ \text { NP-40 } & \text { Tergitol-type NP-40 } \\ \text { (nonylphenoxypolyethoxylethanol) } & \text { Peroxisome proliferator-activated } \\ \text { PGC-1 } \alpha \text { mRNA } & \text { receptor- } \gamma \text { coactivator messenger ribo- } \\ & \text { nucleic acid } \\ \text { PFK } & \text { Phosphofructokinase } \\ \text { PVDF } & \text { Polyvinylidene difluoride } \\ \text { ROS } & \text { Reactive oxygen species } \\ \text { RST } & \text { Repeated sprint test } \\ \text { SDS } & \text { Sodium dodecyl sulphate } \\ \text { SET } & \text { Speed endurance training } \\ \text { SOD1, SOD2 } & \text { Superoxide dismutase } 1 \text { and } 2 \\ \text { SSG } & \text { Small-sided games } \\ \text { TBST } & \text { Tris-buffered saline including Tween-20 } \\ \text { TCA cycle } & \text { Tricarboxylic acid cycle } \\ \text { YD } & \text { Total distance } \\ & \text { Yo-Yo Intermittent Recovery test level } \\ & \end{array}$

\section{Introduction}

Human skeletal muscle has a high plasticity and adapts to various exercise modalities due to specific training-induced stimuli and the type and magnitude of these adaptations impact on high-intensity exercise (Nader and Esser 2001). For example, 2-6 weeks of high-intensity intermittent training termed 'speed endurance training' increased mitochondrial protein content and maximal activity of key enzymes
(Burgomaster et al. 2008; Gibala et al. 2006), whereas mitochondrial enzyme activity remained constant after 6 weeks of continuous training at a lower exercise intensity (Cochran et al. 2014). Speed endurance training for periods of 2-9 weeks has been extensively studied (Bangsbo et al. 2009; Christensen et al. 2011; Gunnarsson et al. 2013; Laursen and Jenkins 2002; Mohr et al. 2007; Thomassen et al. 2010) and has been shown to improve high-intensity intermittent exercise performance (Gibala et al. 2012; Iaia and Bangsbo 2010). Improved muscle function may possibly be caused by an increased expression of muscle ion transporters, such as the $\mathrm{Na}^{+}-\mathrm{K}^{+}$ATPase, monocarboxylate transporters and the $\mathrm{Na}^{+} / \mathrm{H}^{+}$exchanger, which may facilitate ion handling capacity. Moreover, speed endurance training has been shown to elicit larger performance gains than sprint training $(15 \times 6 \mathrm{~s}$ sprints) (Mohr et al. 2007) and endurance training (prolonged submaximal runs) (Iaia et al. 2008). Moreover, muscle ion transport capacity and highintensity exercise performance are improved with the inclusion of speed endurance training, even when the training volume is markedly reduced (Iaia et al. 2008; Thomassen et al. 2010), or when speed endurance training is added to normal training (Gunnarsson et al. 2013). In the past studies, speed endurance training protocols have been included at the expense of less intensive training. However, it is currently unknown if additional speed endurance training elicits a different muscle and performance response compared to additional training at moderate intensity in high-intensity athletes such as competitive soccer players. In competitive soccer, different training modalities are applied (Ade et al. 2014), but a major part of the fitness training is conducted as small-sided games (Dellall et al. 2011). However, limited information exists on the efficiency of this training modality compared to more controlled running drills. In a study by Ade et al. (2014), the characteristics of speed endurance running and small-sided game where compared and marked differences were observed. However, no study has yet tested the muscle and performance adaptations of speed endurance versus small-sided game training.

In a high-intensity intermittent sport such as soccer, the physical demands are complex, encompassing both high endurance capacity and fatigue resistance during highintensity exercise (Fransson et al. 2017; Mohr et al. 2005). Endurance performance in a soccer game is related to muscle oxidative capacity, while muscle $\mathrm{Na}^{+}-\mathrm{K}^{+}$ATPase protein expression displays a strong correlation to high-intensity exercise performance in a game (Mohr et al. 2016b). As a consequence of these observations, studies relating adaptations in both endurance and high-intensity exercise performance to muscular adaptations are highly warranted.

During soccer exercise the oxidative stress is highly upregulated (Mohr et al. 2016a) challenging antioxidative enzymes such as superoxide dismutase (SOD) and catalase 
(CAT) that prevent oxidative damage (Jackson et al. 2011). Exercise training may increase the skeletal muscle antioxidative capacity, as evidenced by upregulated activity in GPX, SOD1 and SOD2 in untrained populations (Gliemann et al. 2014). However, limited studies have addressed whether the muscular antioxidant capacity is augmented by speed endurance training in an athletic population. High-intensity interval training may upregulate the muscle antioxidative capacity and lower systemic oxidative stress (Atalay et al. 1996), even after just a very brief training exposure (e.g. 3 weeks) (Bogdanis et al. 2013; Scribbans et al. 2014). When high-intensity exercise protocols were compared to continuous endurance training of lower intensity, antioxidant enzymes such as SOD, GPX, and catalase (CAT) seemed to be upregulated to a greater (Songstad et al. 2015; Tucker et al. 2015) or to the same (Lu et al. 2015) extent in the former than in the latter. However, these studies did not include trained athletes, who are likely to have a high muscle antioxidant capacity, and may require additional high-intensity training to induce further redox-dependent adaptations such as mitochondrial biogenesis.

Thus, this study aimed to examine muscle oxidative capacity, ion transporters, and antioxidant adaptations, as well as performance responses to 4 weeks of additional speed endurance training or small-sided game training in trained male soccer players. It was hypothesized that speed endurance training would result in more pronounced adaptations in (1) high-intensity intermittent performance, (2) skeletal muscle oxidative capacity, and (3) muscle ion transporters and antioxidant proteins compared to small-sided game training at moderate exercise intensity.

\section{Methods}

\section{Subjects}

Thirty-nine trained semi-professional male soccer players (mean \pm SD, age $21.1 \pm 2.4$ years; height $184 \pm 7 \mathrm{~cm}$; body mass $77.5 \pm 7.8 \mathrm{~kg}$ ) representing two teams in the third division in Sweden volunteered to participate in the study. The participants represented all outfield positions (central defenders $n=7$, full-backs $n=8$, central midfielders $n=6$, wide midfielders $n=10$, attackers $n=8$ ). The players trained four times a week and did not participate in match play during the intervention period. The intervention was initiated 2 weeks into the pre-season in January 2016. All participants had played competitive soccer for at least 5 years prior to the start of the study. Players who had been injured within a period of 6 weeks prior to the start of the study were excluded from the study. All participants were informed of potential risks and discomforts associated with the experiment before giving their written consent to participate according to the guidelines of the Helsinki Declaration. The study was approved by the local ethics committee in Gothenburg (Dnr: 687-15).

\section{Experimental design}

The study applies a randomized controlled design. The participants were randomized to a speed endurance training group (SET; $n=21$ ) or a small-sided game training group (SSG; $n=18$ ). Players from the two teams were randomized within teams and playing position to ensure and equal representation of both intervention groups. The two different types of training were added to the players' normal training programs three times a week for 4 weeks in total. We have chosen to compare SET and SSG, since pilot studies have demonstrated a markedly higher exercise intensity during SET compared to SSG, which also is supported by Mohr and Krustrup (2016). Pre and post intervention physical performance tests were performed to measure the impact of the two intervention training protocols on high-intensity exercise performance. Moreover, a muscle biopsy was obtained pre and post intervention from the $m$. vastus lateralis of the dominant leg. The muscle tissue was analysed for metabolic enzyme maximal activity and expression of a wide range of skeletal muscle proteins. In addition, activity pattern during training was assessed and capillary blood samples were taken during training and analysed for blood lactate concentration.

\section{Experimental protocol}

SET $(n=21)$ performed speed endurance production training (Mohr and Krustrup 2016), three times a week for a 4-week period. The training comprised a $20-\mathrm{m}$ straight forward run and $90^{\circ}$ turn followed by a $10-\mathrm{m}$ forward run and $180^{\circ}$ turn, then another $20-\mathrm{m}$ forward run, another $180^{\circ}$ turn, and finally a 40-m forward run. This specific drill was chosen after pilot testing with GPS technology and with feedback from the coaches. Participants in SET were informed to run with maximum effort during the entire drill and were continuously verbally encouraged. The drill was performed individually as a time trial drill in 30-s intervals separated by $150 \mathrm{~s}$ of passive recovery. The course of the drill ensured that players could perform the drill several times without stopping to ensure that the drill lasted exactly 30 -s. The number of exercise intervals was six during the first intervention week, eight during the second and third weeks, and ten during the fourth week. The SSG group performed a 6-a-side soccer game with goal keepers on a pitch $40 \mathrm{~m}$ long and $32 \mathrm{~m}$ wide three times a week for 4 weeks (Dellal et al. 2011). Pilot studies showed that this specific drill had a markedly lower exercise intensity compared to SET. The training was performed in two intervals lasting $7 \mathrm{~min}$ in the 
first week, two intervals lasting $8 \mathrm{~min}$ in the second and third weeks, and two intervals of $9 \mathrm{~min}$ in the fourth week. The participants had a passive recovery interval of $2 \mathrm{~min}$ between exercise intervals. The 6-a-side games were played with normal rules and players were verbally encouraged. The two different drills were performed at the end of the normal training ( $\sim 60 \mathrm{~min})$ three times a week. The normal training included a $\sim 15$-min warm-up, $\sim 15$ min of technical training, and $\sim 30$ min of tactical training. The players were familiarized with the drills prior to the study. The intervention took place during the pre-season and was conducted outdoors on an artificial pitch. The environmental temperature during the intervention period was $3-8{ }^{\circ} \mathrm{C}$. Forty-five players started the study. There were six drop-outs due to injury $(n=4)$ or illness $(n=2)$. These players were excluded from the measures and analysis, giving a final sample of 39. During the study, participants were instructed to follow their usual diet before all testing and training sessions.

\section{Muscle analyses}

Twelve players did not give informed consent to have muscle biopsies taken but underwent all other measurements. Thus, 27 participants had a muscle biopsy taken $(\sim 70-120 \mathrm{mg}$ wet weight) in resting conditions a week before the start of the intervention. The biopsies were obtained with the subjects lying in the supine position on a portable bed. This procedure was repeated in the week after the intervention 3 days after the last training session. The muscle tissue was immediately frozen in liquid nitrogen and stored at $-80{ }^{\circ} \mathrm{C}$. The frozen sample was weighed after freeze-drying as well as $1 \mathrm{~h}$ later to correct for the water content. After freeze-drying, the muscle samples were dissected free of blood, fat, and connective tissue. Next, 1-2 mg dry weight muscle tissue was extracted in $1 \mathrm{M} \mathrm{HCl}$, hydrolyzed at $100{ }^{\circ} \mathrm{C}$ for $3 \mathrm{~h}$, and the glycogen content determined using the hexokinase method. Maximal citrate synthase (CS), 3-hydroxyacyl-CoA-dehydrogenase (HAD), and phosphofructokinase (PFK) activities were determined fluorometrically in triplicate for each biopsy on a separate piece of muscle from the biopsy, as described by Lowry (Lowry and Passonneau 1972), and these analyses displayed CV values between 4 and $7 \%$.

\section{Western blotting}

The protein expression was determined as described by Thomassen et al. (Thomassen et al. 2010). In short, $\sim 2 \mathrm{mg}$ of the dissected human muscle tissue was homogenized in duplicate for each biopsy (Qiagen Tissuelyser II, Retsch $\mathrm{GmbH}$, Haan, Germany) in a fresh batch of buffer containing (in $\mathrm{mM}$ ): $10 \%$ glycerol, $20 \mathrm{Na}$-pyrophosphate, $150 \mathrm{NaCl}$, 50 HEPES (pH 7.5), 1\% NP-40, $20 \beta$-glycerophosphate, 2 Na3VO4, 10 NaF, 2 PMSF, 1 EDTA (pH 8), 1 EGTA (pH 8),
$10 \mu \mathrm{g} / \mathrm{ml}$ aprotinin, $10 \mu \mathrm{g} / \mathrm{ml}$ leupeptin, and 3 benzamidine. Afterwards, the samples were rotated end over end for $1 \mathrm{~h}$ at $4{ }^{\circ} \mathrm{C}$, centrifuged at $18,320 \mathrm{~g}$ for $20 \mathrm{~min}$ at $4{ }^{\circ} \mathrm{C}$, and the supernatant (lysate) used for further analysis. Total protein concentration in each sample was determined by a bovine serum albumin (BSA) standard kit (Pierce), and samples were mixed with $6 \times$ Laemmli buffer $(7 \mathrm{ml} 0.5 \mathrm{M}$ Tris-base, $3 \mathrm{ml}$ glycerol, $0.93 \mathrm{~g}$ DTT, $1 \mathrm{~g} \mathrm{SDS}$, and $1.2 \mathrm{mg}$ bromophenol blue) and $\mathrm{ddH}_{2} \mathrm{O}$ to obtain similar concentrations in all samples.

An equal amount of total protein was loaded in each well of pre-casted gels (Bio-Rad Laboratories, USA) and all samples from each subject were loaded side by side on the same gel. Proteins were separated according to their molecular weight by sodium dodecyl sulphate polyacrylamide gel electrophoresis (SDS-PAGE) and then transferred semi-dry to polyvinylidene difluoride (PVDF) membranes (Bio-Rad). The membranes were blocked in either $2 \%$ skimmed milk or 3\% BSA in Tris-buffered saline including $0.1 \%$ Tween20 (TBST) before overnight incubation in primary antibody at $4{ }^{\circ} \mathrm{C}$. Subsequently, the membranes were washed for $2 \times 10 \mathrm{~min}$ in TBST and incubated for $1 \mathrm{~h}$ at room temperature in horseradish peroxidase (HRP)-conjugated secondary antibody. The membranes were then washed for $3 \times 15 \mathrm{~min}$ in TBST before the bands were visualized with ECL (Millipore) and recorded with a digital camera (ChemiDoc MP Imaging System, Bio-Rad Laboratories, USA). Quantification of the Western blot band intensity was carried out using Image Lab version 4.0 (Bio-Rad Laboratories, USA), and the mean of samples A and B in arbitrary units was used as the final result estimating the protein expression in each subject. To evaluate intervention-induced changes in protein expression, post versus pre, band signal intensity ratios were calculated for each individual and values $\geq 3$ excluded from further analysis to avoid statistical type II errors.

Prior to the final analyses, the primary antibodies were optimized using human mixed muscle standard lysates to ensure that the band signal intensity was located on the linear part of the specific antibody standard curve. The primary antibodies used to detect the expression of the investigated proteins were diluted in either $2 \%$ skimmed milk [polyclonal $\mathrm{Na}^{+}-\mathrm{K}^{+}$ATPase $\alpha_{2}$ (07-674, Millipore), monoclonal $\beta_{1}$ (MA3-930, Thermo Scientific), polyclonal FXYD1 (13721-1-AP, Datasheet), polyclonal MCT4 (AB3316P, Millipore), polyclonal SOD2 (06-984, Millipore), polyclonal CAT (ab1877, Abcam), polyclonal GLUT4 (PA1-1065, Thermo Fisher Scientific) and polyclonal GS (3893, Cell Signaling Technology)] or 3\% BSA [monoclonal $\mathrm{Na}^{+}-\mathrm{K}^{+}$ ATPase $\alpha_{1}$ (alfa6F, Developmental Study Hydridoma Bank, University of Iowa, USA), polyclonal SOD1 (574597, Millipore) and monoclonal NHE1 (MAB3140, Chemicon)] in TBST. Antibodies targeting SOD1 and SOD2 were kindly provided by Prof. H. Pilegaard, University of Copenhagen. 
Applied secondary antibodies were HRP-conjugated goat anti-rabbit (4010-05, Southern Biotech), rabbit anti-sheep (P-0163, DAKO) and goat anti-mouse (P-0447, DAKO). The muscle buffer capacity was measured after having adjusted the $\mathrm{pH}$ of the sample to 7.1 with $0.01 \mathrm{M} \mathrm{NaOH}$. The sample was titrated to $\mathrm{pH} 6.0$ by serial additions of $0.01 \mathrm{M} \mathrm{HCl}$, followed by titration back to $\mathrm{pH} 7.1$ by serial additions of $0.01 \mathrm{M} \mathrm{NaOH}$. The $\mathrm{pH}$ was assessed after each addition. The non- $\mathrm{HCO}_{3}$ physiochemical buffer capacity was determined from the number of moles of $\mathrm{H}^{+}$required to change the $\mathrm{pH}$ from 7.1 to 6.5 and was expressed as millimoles $\mathrm{H}^{+}$per kilogram dry weight per unit of $\mathrm{pH}$.

\section{Physical and physiological training response}

During a representative intervention training session in week 3 , blood samples were obtained from the fingertip for blood lactate analysis according to standard procedure (Pettersen et al. 2014) to have an indication of the glycolytic loading in the two training interventions. The baseline blood was taken 5 min before normal training. In SET, blood was then taken after intervals 4 and 8 analogous to previous studies (Ade et al. 2014), while in the SSG group blood was obtained after the first and last intervals. Capillary blood was frozen and stored at $-80{ }^{\circ} \mathrm{C}$ until analysed for lactate using a Biosen analyzer (Biosen C-line, EKF-diagnostic GmbH, Magdeburg, Germany; see Pettersen et al. 2014).

Activity pattern characteristics during the additional training were quantified using a 10-Hz S5 global positioning system (GPS) (Catapult Innovations, Melbourne, Australia) on three occasions per player (in weeks 1,2 and 3). This was done to compare the external physical loading of the two training interventions (see also Mohr and Krustrup 2016). The GPS units were placed between the shoulder blades in a harness tight to the body to restrict movement artifact. The GPS has previously been shown to provide a valid and reliable measure of instantaneous velocity during acceleration, deceleration, and constant motion (Varley et al. 2012). Time motion characteristics were quantified as total distance (TD), high-intensity running distance (HIR), and high-speed running distance (HSR), and set at $>0 \mathrm{~km} / \mathrm{h},>14 \mathrm{~km} / \mathrm{h}$, and $>21 \mathrm{~km} / \mathrm{h}$, respectively (see Fransson et al. 2017). Intense accelerations (Ia) and intense decelerations (Id) were also analysed and set at $>3 \mathrm{~m} / \mathrm{s}^{2}$.

\section{Physical performance tests}

Pre and post intervention, the participants performed a repeated sprint test (RST) comprising $5 \times 30$-m straight-line sprints separated by $25 \mathrm{~s}$ of active recovery (easy jogging back to the start line) (Nybo et al. 2013). The test has been shown to be reliable (Castagna et al. 2017) and to possess a high reproducibility (CV < 1\%; Bangsbo and Mohr 2012).
RST performance was determined as mean sprinting time, which has been shown to be reliable (Spencer et al. 2006). Also a fatigue index was calculated as the percentage decline in sprint performance from the first to the last sprint. The test was chosen as a measure of repeated sprint ability in relation to soccer (Bangsbo and Mohr 2012). The participants also performed an arrowhead agility test (AAT) consisting of four trials, two right and two left, according to previous studies (Di Mascio et al. 2015; Noon et al. 2015). This test was applied as a measure of soccer-specific agility and has a high reproducibility $(\mathrm{CV}<1 \%$ Bangsbo and Mohr 2012; Di Mascio et al. 2015). Cones are placed in an arrowhead shape, with one set of cones indicating the start and finish line. The RST and AAT were performed in an indoor hall with a temperature of $\sim 20^{\circ} \mathrm{C}$. The sprint times were measured by photocell gates placed $1.0 \mathrm{~m}$ above ground using Muscle Lab V8 (Bosco System, Rome, Italy) photocells with a precision of $0.001 \mathrm{~s}$. Each sprint was initiated from a standing position with the arms raised to chest height $50 \mathrm{~cm}$ behind the photocell gate, which started a digital timer. The time of each sprint was recorded and total sprint time calculated. A fatigue index was also calculated between the fastest time and the slowest sprint in the RST as well as the accumulated total time of the five sprints. The participants were familiarized with the tests in two pre-trials prior to commencement of the study. Finally, pre and post intervention with 3 days of recovery after the RST and AH, a Yo-Yo intermittent recovery test level 2 (Yo-Yo IR2) was performed following a 10-min standardized warm-up (see Bangsbo and Mohr 2012). The Yo-Yo IR2 test has a high sensitivity and a relatively high reproducibility $(\mathrm{CV}=9.6 \%$, Krustrup et al. 2006) and is correlated to high-intensity running in a soccer game as well as muscle variables of importance for fatigue resistance during intense exercise (Mohr et al. 2016b). The test was performed outside on artificial grass at an environmental temperature of $\sim 4-8{ }^{\circ} \mathrm{C}$. The test consists of repeated $2 \times 20$-m runs back and forth between a start and finish line at progressively increasing speeds until exhaustion, controlled by audio bleeps. Between each running bout, the participants have a 10 -s active recovery period in which they have to jog around a cone placed $5 \mathrm{~m}$ behind the starting line. The participants run until exhaustion, as previously described (Bangsbo and Mohr 2012). Yo-Yo IR2 testing was part of the clubs' test battery, so the participants were familiar with the test procedures.

\section{Statistical analyses}

Data are presented as means \pm SD. Differences in change score in physical test performance and muscle responses between SET and SSG, as well as within-group differences, were evaluated using a two-way ANOVA test. Activity profiles and training responses were compared using a two-way 
ANOVA with repeated measurements. When a significant interaction was detected, data were subsequently analysed using a Newman-Keuls post hoc test. 95\% confidence intervals are presented and effect size (ES; Cohens d calculation) was used to assess the magnitude of the differences and considered trivial $(<0.2)$, small $(0.2-0.6)$, moderate $(0.6-1.2)$, large (1.2-2.0) and extremely large (>2.0) as suggested by Hopkins et al. (2009). A significance level of 0.05 was chosen.

\section{Results}

\section{Exercise training}

The SSG group $(n=13)$ covered $24 \%$ greater $(P<0.05)$ distance in total during the assessed intervention trainings compared to SET ( $n=17$; Table 1$)$. However, SET covered approximately four- and 16 -fold more $(P<0.05)$ highintensity and high-speed running, respectively, than SSG (Table 1). In addition, the SET intervention induced 41 and $163 \%$ more intense accelerations and decelerations in comparison to SSG based on the assessed sessions (Table 1). Finally, capillary blood lactate concentrations during SET $(n=16)$ were more than twice as high in comparison to SSG $(n=12$; Table 1).

\section{Muscular metabolic enzyme expression and substrate level}

Skeletal muscle CS maximal activity increased $(\mathrm{ES}=1.6$, $\mathrm{CI}=9.2-3.1, P<0.05)$ over the intervention period from $25.5 \pm 3.1$ to $30.0 \pm 3.1 \mu \mathrm{mol} \cdot \mathrm{g}^{-1} \cdot \mathrm{min}^{-1}$ in SET $(n=15)$ only, with a larger $(P<0.05)$ change score compared to SSG $(n=11$; Fig. 1$)$. Muscle HAD maximal activity was also elevated $(\mathrm{ES}=1.1, \mathrm{CI}=5.1-1.3, P<0.05)$ post intervention in SET $\left(15.3 \pm 1.9\right.$ to $18.5 \pm 4.0 \mu \mathrm{mol} \cdot \mathrm{g}^{-1} \cdot \mathrm{min}^{-1}$;

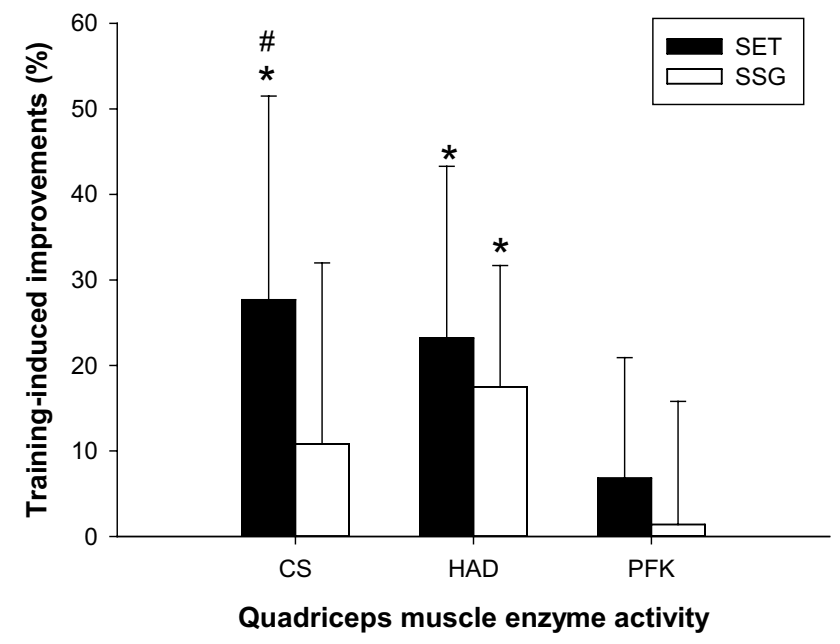

Fig. 1 Relative change from pre to post intervention in citrate synthase (CS), 3-hydroxyacyl-CoA-dehydrogenase (HAD), and phosphofructokinase (PFK) maximal enzyme activity determined in muscle tissue from vastus lateralis muscle in $\operatorname{SET}(n=15$; solid bars) and SSG ( $n=11$; open bars). "Significant between-group differences in change score. ${ }^{*}$-Significant within-group difference from pre to post intervention. Significance level $P<0.05$. Data are means \pm SD

$n=15)$ and in SSG $(\mathrm{ES}=1.3, \mathrm{CI}=6.4-1.4)(15.7 \pm 2.8$ to $\left.19.5 \pm 3.0 \mu \mathrm{mol} \cdot \mathrm{g}^{-1} \cdot \mathrm{min}^{-1} ; n=11\right)$ with no betweengroups difference (Fig. 1). Muscle PFK maximal activity showed no changes between pre and post analysis and no between-groups difference (Fig. 1). GLUT-4 protein expression responded in SSG $(\mathrm{ES}=0.6, \mathrm{CI}=5-75 \%)$ $(40 \pm 54 \% ; n=12 ; P<0.05)$, with no changes in SET (Fig. 2b), while GS protein expression showed a negative change score $(P<0.01)$ of $-22 \pm 30 \%(n=15)$ in SET (ES $=0.2, \mathrm{CI}=-38$ to $-5 \%$ ) with no change in SSG (Fig. 2b). Resting muscle glycogen concentration was $679 \pm 91$ and $678 \pm 85 \mathrm{mmol} \cdot \mathrm{kg}^{-1}$ d.w. in SSG (in front of $(n=12))$, pre intervention, but was elevated $(P<0.05)$ to $758 \pm 143$ and $853 \pm 189 \mathrm{mmol} \cdot \mathrm{kg}^{-1}$ d.w. post intervention. Resting muscle glycogen concentration tended $(P=0.09)$ to increase more in SSG than in SET.

Table 1 Activity pattern and blood lactate during training

\begin{tabular}{|c|c|c|c|c|c|}
\hline Group & $\mathrm{TDC}(\mathrm{m})$ & $\operatorname{HIR}(\mathrm{m})$ & $\operatorname{HSR}(\mathrm{m})$ & $\mathrm{Ia}(n)$ & $\mathrm{Id}(n)$ \\
\hline $\operatorname{SET}(n=17)$ & $1364 \pm 84^{*}$ & $826 \pm 102 *$ & $239 \pm 53 *$ & $38 \pm 9 *$ & $50 \pm 8^{*}$ \\
\hline $\operatorname{SSG}(n=13)$ & $1683 \pm 348$ & $180 \pm 133$ & $14 \pm 15$ & $27 \pm 14$ & $19 \pm 11$ \\
\hline Group & Baseline & Post 4-min & Post 8-min & & \\
\hline \multicolumn{6}{|c|}{ Blood lactate concentration $\left(\mathrm{mmol} \cdot \mathrm{L}^{-1}\right)$} \\
\hline $\operatorname{SET}(n=16)$ & $3.4 \pm 1.7$ & $11.8 \pm 2.8^{*}$ & $13.7 \pm 3.4^{*}$ & & \\
\hline $\operatorname{SSG}(n=12)$ & $2.6 \pm 1.9$ & $4.7 \pm 2.0$ & $4.8 \pm 2.3$ & & \\
\hline
\end{tabular}

TDC Total distance covered, HIR high-intensity running, HSR high speed running, Ia intense accelerations, Id decelerations (upper panel) and blood lactate concentrations (lower panel) during training in SET and SSG

$*$ Significant different from SSG. Significant level $P<0.05$. Data are means \pm SD 

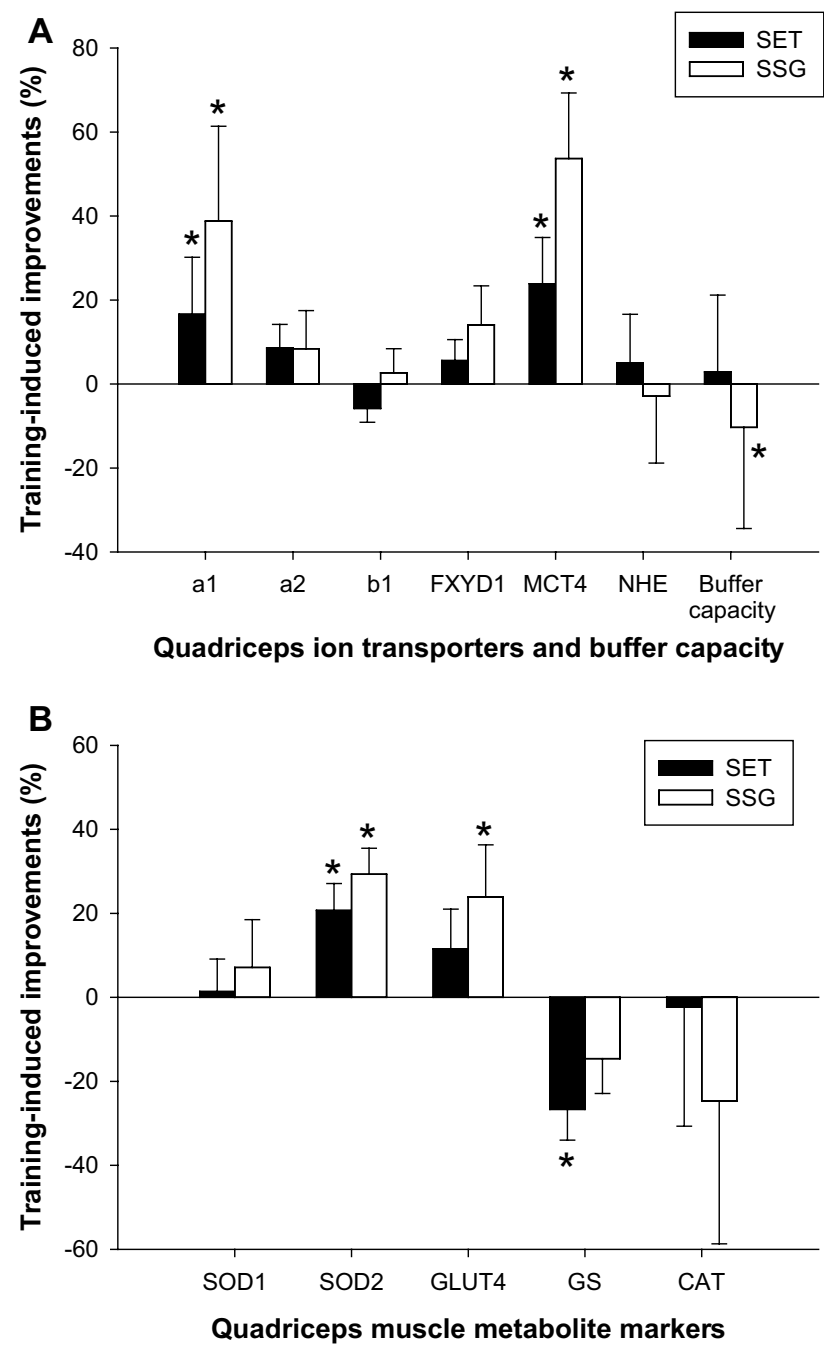

Fig. 2 Relative change from pre to post intervention in $\mathrm{Na}^{+}-\mathrm{K}^{+}$ ATPase $\alpha_{1}, \alpha_{2}, \beta_{1 \text { and }}$ FXYD1, MCT4 and NHE1 protein expression, as well as buffer capacity (a), and SOD1, SOD2, GLUT4, GS and CAT protein expression (b) determined in muscle tissue from vastus lateralis muscle in SET ( $n=15$; solid bars) and SSG $(n=12$; open bars). "Significant between-group differences in change score. *Significant within-group difference from pre to post intervention. Significance level $P<0.05$. Data are means \pm SD

\section{Muscular ion-regulatory enzyme expression}

Protein expression for the $\alpha_{1} \mathrm{Na}^{+}-\mathrm{K}^{+}$ATPase subunit increased in SET $(\mathrm{ES}=0.5, \mathrm{CI}=46-34 \%)(19 \pm 26 \%$; $n=15 ; P<0.05)$ and SSG $(\mathrm{ES}=0.7, \mathrm{CI}=13-63 \%)$ $(37 \pm 41 \% ; n=12 ; P<0.01)$, with a tendency $(P=0.07)$ for a greater change score in SSG (Fig. 2a). In contrast, no between-group or within-group differences were detected in the $\alpha_{2}, \beta_{1}$ and FXYD1 $\mathrm{Na}^{+}-\mathrm{K}^{+}$ATPase subunits post intervention (Fig. 2a). MCT4 protein expression was upregulated in response to both interventions (SET: $30 \pm 41 \% ; n=15 ; \mathrm{ES}=0.3, \mathrm{CI}=7-52 \%, P<0.05$; SSG: $61 \pm 49 \% ; n=12 ; \mathrm{ES}=0.7, \mathrm{CI}=30-92 \%, P<0.01)$, with

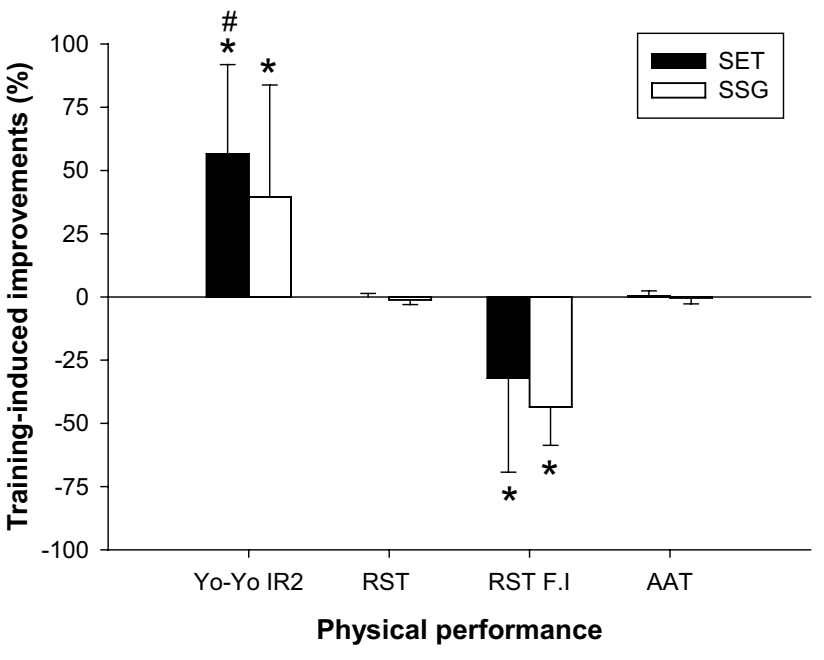

Fig. 3 Relative change from pre to post intervention in Yo-Yo intermittent recovery test, level 2 (Yo-Yo IR2), repeated sprint test (RST), and RST fatigue index $\left(\mathrm{RST}_{\mathrm{FI}}\right)$ and arrowhead agility test (AAT) performance in SET ( $n=21$; solid bars) and SSG ( $n=18$; open bars). ${ }^{\#}$ Significant between-group differences in change score. *Significant within-group difference from pre to post intervention. Significance level $P<0.05$. Data are means \pm SD

no between-group effects (Fig. 2a). No between-group or within-group effects were observed in NHE1 protein expression or muscle buffer capacity (Fig. 2a).

\section{Muscular antioxidative enzyme expression}

SOD2 protein expression increased in SET $(E S=0.8$, $\mathrm{CI}=10-46 \%)$ and SSG $(\mathrm{ES}=1.1, \mathrm{CI}=19-55 \%)[28 \pm 32 \%$ $(n=15)$ and $37 \pm 29 \%(n=12)$, respectively; $P<0.05]$, while no intervention-induced changes occurred in protein expression of SOD1 (Fig. 2b). The SET and SSG interventions did not affect CAT protein expression (Fig. 2b).

\section{Exercise performance}

At baseline Yo-Yo IR2 performance was $569 \pm 147$ and $563 \pm 145 \mathrm{~m}$ in SET and SSG, respectively. Yo-Yo IR2 performance increased in SET $(\mathrm{ES}=1.9, \mathrm{CI}=-386.8$ to $-357.9, P<0.05)(n=21)$ and SSG $(\mathrm{ES}=1.3$, $\mathrm{CI}=-387.1$ to $158.0, P<0.05)(n=18)$ by $323 \pm 125$ and $222 \pm 113 \mathrm{~m}$, respectively, with a $39 \%$ greater change score $(P<0.05)$ in SET than in SSG (Fig. 3). RST performance was unaltered in both SET and SSG, as mean sprint time did not change during the intervention. However, the fatigue index improved $(P<0.001)$ in both groups (Fig. 3 ). AAT performance did not change during the intervention period (Fig. 3). 


\section{Discussion}

The principal findings of the present study were that 4 weeks of additional speed endurance training induced more pronounced improvement of shuttle-run performance and CS maximal activity, whereas small-sided games tended to induce more pronounced increases in the expression of $\mathrm{Na}^{+}-\mathrm{K}^{+}$ATPase $\alpha_{1}$ and GLUT4 as well as a higher level of muscle glycogen. The observed increases of HAD maximal activity, as well as MCT4 and SOD2 expression were comparable between groups. Thus, the training outcome is clearly different between the applied protocols in terms of exercise capacity, as well as muscle phenotype.

In the present study, SET performed as all-out 30-s runs induced superior effects on skeletal muscle oxidative capacity compared to SSG training in well-trained soccer players. SSG are highly applied in competitive soccer training compared to SET (Dellal et al. 2011), but the two methods have not been compared in relation to performance and physiological impact. We demonstrate that CS maximal activity in the quadriceps muscle showed greater responses in SET than in SSG (see Fig. 1). In contrast, muscle HAD maximal activity was enhanced to a similar extent after both training protocols. Thus, these findings indicate that exercise training-induced adaptations in skeletal muscle oxidative capacity are not strongly associated with metabolic flow during training. For example, the SSG approach has been shown to have a marked aerobic component (Halouani et al. 2014) which is also supported by a $25 \%$ longer running distance in SSG than SET (see Table 1). In divergence, SET demonstrated a markedly higher exercise intensity as well as glycolytic activity, as observed in previous studies (Iaia et al. 2009; Mohr et al. 2007). Despite this, and in contrast to the oxidative markers, muscle PFK activity was not upregulated in response to the intense training regime, which is in line with other speed endurance training studies (Harmer et al. 2000; Mohr et al. 2007; Nordsborg et al. 2015), supporting the notion above. The finding of upregulated mitochondrial capacity after SET has been reported in several other studies in both untrained individuals (Burgomaster et al. 2008; Gibala et al. 2006; Nordsborg et al. 2015) and trained athletes (Iaia and Bangsbo 2010; Skovgaard et al. 2016). SET appears to increase muscle oxidative capacity when added to normal training (Gunnarsson et al. 2013), as in the present study, and when performed in conjunction with lowered training volume (Christensen et al. 2011; Nordsborg et al. 2015). Recently, MacInnis et al. (MacInnis et al. 2017) also demonstrated that single-leg cycling performed in an interval compared to a continuous manner elicited superior skeletal muscle mitochondrial adaptations despite equal total work. Collectively, this research supports the present study that SET upregulates oxidative capacity in skeletal muscle and appear to be superior to endurance-based training even in well-trained athletes. A potential mechanism may be that high-intensity interval training enhances aerobic metabolism (Harmer et al. 2000) via upregulation of PGC- $1 \alpha$ mRNA expression (Nordsborg et al. 2010; Skovgaard et al. 2016) and subsequently improved mitochondrial biogenesis.

An interesting finding in the current study was a nearly $40 \%$ greater improvement in Yo-Yo IR2 test performance in the SET compared to the SSG training group. In contrast, RST and agility performance was unaltered, but the fatigue index in the RST displayed comparable improvement in both SET and SSG. It should be noted that the application of fatigue indexes in RST is questionable (Oliver 2009). There is strong backing in the literature for the proposition that SET increases high-intensity exercise performance in both habitually active (Mohr et al. 2007) and trained populations (Iaia et al. 2009; Mohr and Krustrup 2016; Thomassen et al. 2010). For example, it was demonstrated by Thomassen et al. (Thomassen et al. 2010) that repeated sprint ability improved after only 2 weeks of SET even after the training volume was markedly reduced in well-trained soccer players. Fatigue during high-intensity exercise has been linked to depolarization of the resting muscle membrane potential caused by disturbance in the muscle ion homeostasis, with a large $\mathrm{K}^{+}$efflux from the muscle cell and accumulation in the muscle interstitial fluid being suggested to play a central role (McKenna et al. 2008). Thus, an upregulation in muscle $\mathrm{Na}^{+}-\mathrm{K}^{+}$ATPase protein expression, may be beneficial for delaying the onset of fatigue during intense exercise. However, in the present study, SET and SSG training groups improved (19 and 37\%, respectively) the protein expression of the $\alpha_{1} \mathrm{Na}^{+}-\mathrm{K}^{+}$ATPase subunit, with a tendency $(P=0.07)$ for more marked improvement in the SSG group (Fig. 2a), demonstrating that the more pronounced improvements in Yo-Yo IR2 performance in SET are unrelated to the altered $\alpha_{1} \mathrm{Na}^{+}-\mathrm{K}^{+}$ATPase expression.

Muscle MCT4 protein expression increased in both training groups with no between-group differences, while no changes occurred in NHE1 protein expression (Fig. 2a). Thus, the muscle lactate ${ }^{-}$and $\mathrm{H}^{+}$regulation capacity were partly improved by both interventions, despite a decline in muscle buffer capacity after the SSG intervention (Fig. 2a). The decline in buffer capacity may have influenced the inferior exercise performance adaptations in SSG in comparison to SET. Blood lactate concentration during training was markedly higher in SET than in SSG (see Table 1), indicating a higher muscle lactate production and a potentially greater degree of muscle acidification in SET (Mohr et al. 2007), which potentially have maintained muscle buffer capacity in SET. In contrast, the adaptive response to exercise training in MCT4 and NHE1 does not appear to be highly influenced by the flow rate through these transporters.

Muscle antioxidant capacity was upregulated in both training groups, with SOD2 muscle protein expression 
elevated by 28 and $37 \%$ in SET and SSG, respectively (Fig. 2b). SOD quenches the superoxide anion (Jiang et al. 2014), whereas antioxidant enzymes seem to inhibit the translocation of NF- $\mathrm{KB}$ to the nucleus, thereby contributing to the attenuation of exercise-induced oxidative stress and inflammatory cascades induced by intense exercise (Azevedo-Martins et al. 2003). This is particularly important for high-intensity intermittent exercise, which induces a marked rise in oxidative stress and inflammatory responses (Mohr et al. 2016a). Conventional endurance training may increase the expression and activity of antioxidant enzymes such as GPX, SOD, and CAT in skeletal muscle following several weeks of exposure (Evelo et al. 1992; Fatouros et al. 2004; Oh-ishi et al. 1997). However, similar data from human muscle tissue following high-intensity training regimes such as speed endurance regimes are sparse. One study found that only three speed training sessions induced an elevation in antioxidant status (Shing et al. 2007), which coincides with the elevation in SOD2 protein expression after only 4 weeks of high-intensity intermittent training in our study. The supportive findings on SOD2 following speed endurance training have been reported in two animal studies (Lu et al. 2015; Tucker et al. 2015), and one human study with recreationally active participants (Scribbans et al. 2014). Repeated exposure to intense exercise-induced ROS generation and inflammation is suggested to be a prerequisite for SOD upregulation (Powers et al. 1993), which may indicate that training intensity is an important variable for the adaptive response. However, statistically the two training protocols in the present study were equally effective in upregulating SOD2. The elevated expression in SOD2 proteins has been linked to the muscle oxygen consumption during training (Jenkins et al. 1984), since a close relationship has previously been reported for antioxidant enzymes and adaptation in TCA cycle enzymes (Burgomaster et al. 2006, 2007; Gibala et al. 2012; Laughlin et al. 1990). In the present study, the cytosol-based SOD1 protein remained unaffected by the training intervention, whereas SOD2 located in the mitochondrial intermembrane space increased and may be indicative of interplay between antioxidant reserves and mitochondrial adaptations to training. Our data partly verify this notion, with the SOD2 expression rise which coinciding with the upregulation of muscle oxidative capacity, as evidenced by the rise in CS activity in the SET group. However, no intervention-induced adaptations were detected in SSG despite the $\sim 40 \%$ elevation in SOD2 expression, which speaks in favour of other muscle signalling mechanisms for mitochondrial biogenesis. In addition, no correlation was found between the delta change in CS and SOD2 during the training intervention period (data not shown). Rats bred to have high running capacity were characterized by having high muscle SOD2 activity, suggesting that increased endurance is characterized by an increased molecular network of resistance to oxidative stress (Tweedie et al. 2011). However, in the present study, no relationship was seen between exercise performance adaptation and upregulation of SOD2. Further studies are warranted to elucidate redox adaptations to exercise training in trained human skeletal muscle.

Resting muscle glycogen increased in both groups after the training intervention, which is a common finding in other training studies (Nordsborg et al. 2015; Randers et al. 2010). However, muscle glycogen tended to increase more in SSG compared to SET. This is supported by the fact that muscle glucose transport capacity, marked by GLUT4 protein expression, was enhanced by $40 \%$ in SSG with no change after SET (Fig. 2b), while glycogen synthase protein expression was down regulated in SET. Thus, the SSG intervention was apparently more efficient at improving muscle glycogen storage capacity, despite that no difference was detected in resting glycogen measured in muscle homogenate. In contrast to the present study, a number of studies have found increased muscle GLUT4 content (Little et al. 2010), as well as resting muscle glycogen (Nordsborg et al. 2015), after high-intensity training protocols. However, these studies were not performed with trained athletes, which may partly explain the conflicting findings in our study.

A limitation of the present study is that two interventions are compared without a classical control group, since we wanted to match the training time in the two interventions. Moreover, it was not possible to monitor physical and physiological responses during the entire training period to describe the full external and internal loading, since the players were assessed during a real setting pre-season period.

\section{Conclusions}

In conclusion, added high-intensity intermittent exercise training, organised as speed endurance training drills, improves skeletal muscle oxidative capacity and exercise performance to a greater degree than added moderate intensity training, organised as small-sided soccer games, in welltrained male soccer players, with similar group responses in muscle lactate ${ }^{-} / \mathrm{H}^{+}$cotransporter and antioxidative capacity. In contrast, moderate intensity training increased muscle GLUT4 expression and tended to induce greater upregulation in $\mathrm{Na}^{+}-\mathrm{K}^{+}$ATPase subunit expression and muscle glycogen storage capacity than high-intensity interval training.

Acknowledgements We would like to thank the participants for their commitment and effort, and their clubs and coaches for the positive support. We would also like to express our appreciation for the technical assistance provided by Dr. Thorbjörn Akerström, Dr. Jens Jung Nielsen, Dr. Martin Thomassen and Dr. Malte Nejst Larsen. 


\section{Compliance with ethical standards}

\section{Conflict of interest No conflict of interest.}

Open Access This article is distributed under the terms of the Creative Commons Attribution 4.0 International License (http://creativecommons.org/licenses/by/4.0/), which permits unrestricted use, distribution, and reproduction in any medium, provided you give appropriate credit to the original author(s) and the source, provide a link to the Creative Commons license, and indicate if changes were made.

\section{References}

Ade JD, Harley JA, Bradley PS (2014) Physiological response, timemotion characteristics, and reproducibility of various speedendurance drills in elite youth soccer players: small-sided games versus generic running. Int J Sports Physiol Perform 9:471-479

Atalay M, Seene T, Hänninen O, Sen C (1996) Skeletal muscle and heart antioxidant defences in response to sprint training. Acta Physiol 158:129-134

Azevedo-Martins AK, Lortz S, Lenzen S, Curi R, Eizirik DL, Tiedge M (2003) Improvement of the mitochondrial antioxidant defense status prevents cytokine-induced nuclear factor-kappaB activation in insulin-producing cells. Diabetes 52:93-101

Bangsbo J, Mohr M (2012) Fitness testing in football—fitness training in soccer II. Bangsbosport, Copenhagen

Bangsbo J, Gunnarsson TP, Wendell J, Nybo L, Thomassen M (2009) Reduced volume and increased training intensity elevate muscle $\mathrm{Na}+-\mathrm{K}+$ pump alpha2-subunit expression as well as short- and long-term work capacity in humans. J Appl Physiol (Bethesda, MD:1985) 107:1771-1780. doi:https://doi.org/10.1152/ japplphysiol.00358.2009

Bogdanis $G$ et al (2013) Short-term high-intensity interval exercise training attenuates oxidative stress responses and improves antioxidant status in healthy humans. Food Chem Toxicol 61:171-177

Burgomaster KA, Heigenhauser GJ, Gibala MJ (2006) Effect of shortterm sprint interval training on human skeletal muscle carbohydrate metabolism during exercise and time-trial performance. J Appl Physiol (Bethesda, MD:1985) 100:2041-2047. doi:https:// doi.org/10.1152/japplphysiol.01220.2005

Burgomaster KA, Cermak NM, Phillips SM, Benton CR, Bonen A, Gibala MJ (2007) Divergent response of metabolite transport proteins in human skeletal muscle after sprint interval training and detraining. Am J Physiol Regul Integr Comp Physiol 292:R1970 1976. doi:https://doi.org/10.1152/ajpregu.00503.2006

Burgomaster KA, Howarth KR, Phillips SM, Rakobowchuk M, MacDonald MJ, McGee SL, Gibala MJ (2008) Similar metabolic adaptations during exercise after low volume sprint interval and traditional endurance training in humans. J Physiol 586:151-160

Castagna C, Francini L, Krustrup P, Fenarnandes-Da-Silva J, Povoas SCA, Bernardini A, D'ottavio S (2017) Reliability characteristics and applicability of a repeated sprint ability test in male young soccer players. J Strength Cond Res. doi:https://doi.org/10.1519/ JSC.0000000000002031 (Epub ahead of print)

Christensen PM, Krustrup P, Gunnarsson TP, Kiilerich K, Nybo L, Bangsbo J (2011) $\mathrm{VO}_{2}$ kinetics and performance in soccer players after intense training and inactivity. Med Sci Sports Exerc 43:1716-1724

Cochran AJ et al (2014) Intermittent and continuous high-intensity exercise training induce similar acute but different chronic muscle adaptations. Exp Physiol 99:782-791
Dellal A, Hill-Haas S, Lago-Penas C, Chamari K (2011) Small-sided games in soccer: amateur vs. professional players' physiological responses, physical, and technical activities. J Strength Cond Res Natl Strength Cond Assoc 25:2371-2381. doi:https://doi. org/10.1519/JSC.0b013e3181fb4296

Di Mascio M, Ade J, Bradley PS (2015) The reliability, validity and sensitivity of a novel soccer-specific reactive repeated-sprint test (RRST). Eur J Appl Physiol 115:2531-2542. doi:https://doi. org/10.1007/s00421-015-3247-0

Evelo CT, Palmen NG, Artur Y, Janssen GM (1992) Changes in blood glutathione concentrations, and in erythrocyte glutathione reductase and glutathione S-transferase activity after running training and after participation in contests. Eur J Appl Physiol Occup Physiol 64:354-358

Fatouros IG, Jamurtas AZ, Villiotou V, Pouliopoulou S, Fotinakis P, Taxildaris K, Deliconstantinos G (2004) Oxidative stress responses in older men during endurance training and detraining. Med Sci Sports Exerc 36:2065-2072

Fransson D, Krustrup P, Mohr M (2017) Running intensity fluctuations indicate temporary performance decrement in top-class football. Sci Med Footb 1:10-17. doi:https://doi.org/10.1080/02640414.2 016.1254808

Gibala MJ et al (2006) Short term sprint interval versus traditional endurance training: similar initial adaptations in human skeletal muscle and exercise performance. J Physiol 575:901-911

Gibala MJ, Little JP, MacDonald MJ, Hawley JA (2012) Physiological adaptations to low volume, high intensity interval training in health and disease. J Physiol 590:1077-1084

Gliemann L, Nyberg M, Hellsten Y (2014) Nitric oxide and reactive oxygen species in limb vascular function: what is the effect of physical activity? Free Radic Res 48:71-83

Gunnarsson TP, Christensen PM, Thomassen M, Nielsen LR, Bangsbo J (2013) Effect of intensified training on muscle ion kinetics, fatigue development, and repeated short-term performance in endurance-trained cyclists. Am J Physiol Regul Integr Comp Physiol 305:R811-R821

Halouani J, Chtourou H, Gabbett T, Chaouachi A, Chamari K (2014) Small-sided games in team sports training: a brief review. J Strength Cond Res Natl Strength Cond Assoc 28:3594-3618. doi:https://doi.org/10.1519/JSC.0000000000000564

Harmer AR et al (2000) Skeletal muscle metabolic and ionic adaptations during intense exercise following sprint training in humans. J Appl Physiol 89:1793-1803

Hopkins GW, Marshall WS, Batterham MA, Hanin MJ (2009) Progressive Statistics for Studies in Sports Medicine and Exercise Science. Med Sci Sport Exerc 41:3-12

Iaia FM, Bangsbo J (2010) Speed endurance training is a powerful stimulus for physiological adaptations and performance improvements of athletes. Scand J Med Sci Sports 20(suppl 2):11-23. doi:https://doi.org/10.1111/j.1600-0838.2010.01193.x

Iaia FM et al (2008) Reduced volume but increased training intensity elevates muscle $\mathrm{Na}+-\mathrm{K}+$ pump alpha1-subunit and NHE1 expression as well as short-term work capacity in humans. Am J Physiol Regul Integr Comp Physiol 294:R966-974. doi:https:// doi.org/10.1152/ajpregu.00666.2007

Iaia FM, Rampinini E, Bangsbo J (2009) High-intensity training in football. Int J Sports Physiol Perform 4:291-306

Jackson JR, Ryan MJ, Alway SE (2011) Long-term supplementation with resveratrol alleviates oxidative stress but does not attenuate sarcopenia in aged mice. J Gerontol Ser A Biol Sci Med Sci 66:751-764

Jenkins RR, Friedland R, Howald H (1984) The relationship of oxygen uptake to superoxide dismutase and catalase activity in human skeletal muscle. Int J Sports Med 5:11-14. doi:https://doi.org/10 1055/s-2008-1025872 
Jiang J et al (2014) Antioxidative and cardioprotective effects of total flavonoids extracted from Dracocephalum moldavica L. against acute ischemia/reperfusion-induced myocardial injury in isolated rat heart. Cardiovasc Toxicol 14:74-82. doi:https://doi. org/10.1007/s12012-013-9221-3

Krustrup P, Mohr M, Nybo L, Jensen JM, Nielsen JJ, Bangsbo J (2006) The Yo-Yo IR2 test: physiological response, reliability, and application to elite soccer. Med Sci Sports Exerc 38(9):1666-1673

Laughlin MH, Simpson T, Sexton WL, Brown OR, Smith JK, Korthuis RJ (1990) Skeletal muscle oxidative capacity, antioxidant enzymes, and exercise training. J Appl Physiol (Bethesda, MD:1985) 68:2337-2343

Laursen PB, Jenkins DG (2002) The scientific basis for high-intensity interval training: optimising training programmes and maximising performance in highly trained endurance athletes. Sports Med 32:53-73

Little JP, Safdar A, Wilkin GP, Tarnopolsky MA, Gibala MJ (2010) A practical model of low-volume high-intensity interval training induces mitochondrial biogenesis in human skeletal muscle: potential mechanisms. J Physiol 588:1011-1022. doi:https://doi. org/10.1113/jphysiol.2009.181743

Lowry O, Passonneau JV (1972) A flexible system of enzymatic analysis. Academic, New York, pp 237-249

Lu K, Wang L, Wang C, Yang Y, Hu D, Ding R (2015) Effects of high-intensity interval versus continuous moderate intensity aerobic exercise on apoptosis, oxidative stress and metabolism of the infarcted myocardium in a rat model. Mol Med Rep 12:2374-2382

MacInnis MJ et al (2017) Superior mitochondrial adaptations in human skeletal muscle after interval compared to continuous singleleg cycling matched for total work. J Physiol 595:2955-2968. doi:https://doi.org/10.1113/jp272570

McKenna MJ, Bangsbo J, Renaud J-M (2008) Muscle K+, Na+, and $\mathrm{Cl}$-disturbances and $\mathrm{Na}+-\mathrm{K}+$ pump inactivation: implications for fatigue. J Appl Physiol 104:288-295

Mohr M, Krustrup P (2016) Comparison between two types of anaerobic speed endurance training in competitive soccer players. J Hum Kinet 50:183-192

Mohr M, Krustrup P, Bangsbo J (2005) Fatigue in soccer: a brief review. J Sports Sci 23:593-599

Mohr M, Krustrup P, Nielsen JJ, Nybo L, Rasmussen MK, Juel C, Bangsbo J (2007) Effect of two different intense training regimens on skeletal muscle ion transport proteins and fatigue development. Am J Physiol Regul Integr Comp Physiol 292:R1594-1602. doi:https://doi.org/10.1152/ajpregu.00251.2006

Mohr M et al (2016a) Muscle damage, inflammatory, immune and performance responses to three football games in 1 week in competitive male players. Eur J Appl Physiol 116:179-193. doi:https:// doi.org/10.1007/s00421-015-3245-2

Mohr M, Thomassen M, Girard O, Racinais S, Nybo L (2016b) Muscle variables of importance for physiological performance in competitive football. Eur J Appl Physiol 116:251-262

Nader GA, Esser KA (2001) Intracellular signaling specificity in skeletal muscle in response to different modes of exercise. J Appl Physiol 90:1936-1942

Noon MR, James RS, Clarke ND, Akubat I, Thake CD (2015) Perceptions of well-being and physical performance in English elite youth footballers across a season. J Sports Sci 33:2106-2115. doi:https://doi.org/10.1080/02640414.2015.1081393

Nordsborg NB, Lundby C, Leick L, Pilegaard H (2010) Relative workload determines exercise-induced increases in PGC-1alpha Mrna. Med Sci Sports Exerc 42:1477-1484

Nordsborg NB, Connolly L, Weihe P, Iuliano E, Krustrup P, Saltin B, Mohr M (2015) Oxidative capacity and glycogen content increase more in arm than leg muscle in sedentary women after intense training. J Appl Physiol 119:116-123

Nybo L, Girard O, Mohr M, Knez W, Voss S, Racinais S (2013) Markers of muscle damage and performance recovery after exercise in the heat. Med Sci Sports Exerc 45:860-868. doi:https://doi. org/10.1249/MSS.0b013e31827ded04

Oh-ishi S, Kizaki T, Ookawara T, Sakurai T, Izawa T, Nagata N, Ohno H (1997) Endurance training improves the resistance of rat diaphragm to exercise-induced oxidative stress. Am J Respir Crit Care Med 156:1579-1585. doi:https://doi.org/10.1164/ ajrccm.156.5.96-11035

Oliver JL (2009) Is a fatigue index a worthwhile measure of repeated sprint ability? J Sci Med Sport 12:20-23

Pettersen SA et al (2014) Caffeine supplementation does not affect match activities and fatigue resistance during match play in young football players. J Sports Sci 32:1958-1965. doi:https://doi.org/1 0.1080/02640414.2014.965189

Powers SK, Criswell D, Lawler J, Martin D, Lieu FK, Ji LL, Herb RA (1993) Rigorous exercise training increases superoxide dismutase activity in ventricular myocardium. Am J Physiol 265:H2094-2098

Randers MB et al. (2010) Activity profile and physiological response to football training for untrained males and females, elderly and youngsters: influence of the number of players. Scand J Med Sci Sports 20(suppl 1):14-23 doi:https://doi. org/10.1111/j.1600-0838.2010.01069.x

Scribbans TD et al (2014) Resveratrol supplementation does not augment performance adaptations or fibre-type-specific responses to high-intensity interval training in humans. Appl Physiol Nutr Metab 39:1305-1313

Shing CM, Peake JM, Ahern SM, Strobel NA, Wilson G, Jenkins DG, Coombes JS (2007) The effect of consecutive days of exercise on markers of oxidative stress. Appl Physiol Nutr Metab 32:677-685. doi:https://doi.org/10.1139/h07-051

Skovgaard C, Almquist NW, Bangsbo J (2016) Effect of increased and maintained frequency of speed endurance training on performance and muscle adaptations in runners. J Appl Physiol 2016:00537

Songstad NT, Kaspersen K-HF, Hafstad AD, Basnet P, Ytrehus K, Acharya G (2015) Effects of high intensity interval training on pregnant rats, and the placenta, heart and liver of their fetuses. PloS One 10:e143095

Spencer M, Fitzsimons M, Dawson B, Bishop D, Goodman C (2006) Reliability of a repeated-sprint test for field-hockey. J Sci Med Sport 9:181-184

Thomassen M, Christensen PM, Gunnarsson TP, Nybo L, Bangsbo J (2010) Effect of 2-wk intensified training and inactivity on muscle $\mathrm{Na}+-\mathrm{K}+$ pump expression, phospholemman (FXYD1) phosphorylation, and performance in soccer players. J Appl Physiol (Bethesda, MD:1985) 108:898-905. doi:https://doi.org/10.1152/ japplphysiol.01015.2009

Tucker PS, Briskey DR, Scanlan AT, Coombes JS, Dalbo VJ (2015) High intensity interval training favourably affects antioxidant and inflammation mRNA expression in early-stage chronic kidney disease. Free Radical Biol Med 89:466-472

Tweedie C et al (2011) Lower oxidative DNA damage despite greater ROS production in muscles from rats selectively bred for high running capacity. Am J Physiol Regul Integr Comp Physiol 300:R544-553. doi:https://doi.org/10.1152/ajpregu.00250.2010

Varley MC, Fairweather IH, Aughey RJ (2012) Validity and reliability of GPS for measuring instantaneous velocity during acceleration, deceleration, and constant motion. J Sports Sci 30:121-127 